\title{
Cavalo Campeiro: Passado, presente e futuro do Marchador das Araucárias
}

\section{Campeiro Horse: Past, present and future of the Araucarias Gaited horse}

\author{
Anderson Fernando de Souza ${ }^{1^{*}}$, Joandes Henrique Fonteque ${ }^{2}$, Dirceu Costa ${ }^{3}$ \\ ${ }^{1}$ Faculdade de Medicina Veterinária e Zootecnia, Universidade de São Paulo (USP), São Paulo, SP, Brasil \\ ${ }^{2}$ Departamento de Medicina Veterinária, Centro de Ciências Agroveterinárias, Universidade do Estado de Santa Catarina (UDESC), \\ Lages, SC, Brasil \\ ${ }^{3}$ Serviço de Registro Genealógico, Associação Brasileira de Criadores de Cavalos Campeiro (ABRACCC), Curitibanos, SC, Brasil
}

\section{Resumo}

O Brasil é dotado de um número considerável de raças naturalizadas de animais de produção e equinos que, em grande, parte não são conhecidas ou reconhecidas pelos produtores/população, os quais voltam a atenção às raças exóticas devido ao marketing massivo existente. A formação destas raças não foi fruto de uma estratégia ou planejamento, mas sim oriunda da adversidade e de acontecimentos históricos sucessivos, aliada à dedicação e visão futurista de pessoas que se esforçaram e ainda se esforçam para sua conservação e melhoramento. Com o cavalo Campeiro, que tem origem nos animais trazidos durante as expedições espanholas de 1541, não é diferente. Trata-se de um grupamento genético de grande valor, mas pouco lapidado, em que não há na literatura um resgate histórico sólido e uma análise de sua situação atual. Sendo assim, esse artigo tem por objetivo apresentar uma revisão literária sobre os equinos da raça Campeiro, abordando aspectos históricos, de formação, condições atuais e perspectivas futuras, além de uma matriz SWOT da raça para servir como ferramenta de promoção e fomento a estratégias para a conservação da raça.

Palavras-chave: Raças nativas. Recursos genéticos. Equino.

\begin{abstract}
Brazil has a large number of native breeds of food animals and equines, which in many cases is not known or recognized by the breeders/population, that give attention to the exotic breeds due to massive marketing. The formation of these races did not come from a strategy or planning, but from adversity and successive historical events, combined with the dedication and futuristic vision of people who have struggled and still strive for their conservation and improvement. With Campeiro horses, that originate in the animals brought during the Spanish expeditions of 1541, it is no different. Campeiro horses are a genetic group of
\end{abstract}


great value, but there is not in the literature an adequate historical rescue and an analysis of its current situation. This article aims to present a literary review on the breed of the Campeiro horse, addressing historical aspects, training, current conditions and future perspectives, as well as a SWOT matrix of the breed to serve as a tool to disseminate and promote strategies for the conservation of the breed.

Keywords: Native breeds. Genetic resources. Equine.

\section{Introdução}

Até o ano de 1493, na ocasião da chegada de Cristóvão Colombo, não havia indícios da presença de cavalos nas Américas. Foi com sua segunda viagem, desembarcando na Ilha de São Domingos, no Caribe, que um grupo de dez animais, entre garanhões e éguas, deram início à criação de equinos do novo continente. No Brasil, os primeiros cavalos portugueses desembarcaram dos porões das caravelas em 1534 em São Vicente, SP, em 1535 em Olinda, PE, e em 1541 em Laguna, SC. A partir de então houve progressiva e intensa importação de equídeos, em sua maioria de origem europeia, para auxiliar no desbravamento do Brasil Colônia (Torres e Jardim, 1992).

Santos et al. (1992) citam que as primeiras raças introduzidas eram basicamente de origem hispânica, mas também foram trazidos animais de origem inglesa, berbere, árabe e turca. Sob influência das condições ímpares do Brasil, um país de extensas dimensões com diferentes ecossistemas, permitiu-se a seleção natural dos animais nas diferentes regiões, como o Pampa Gaúcho, o Planalto catarinense, o Pantanal do Mato Grosso, as regiões Sudeste, Nordeste e Norte, que deram origem a várias raças naturalizadas. A modelação destes grupos raciais também é fruto da utilização destes no desenvolvimento das respectivas regiões, promovendo a seleção de tipos de acordo com as funções exercidas pelos cavalos.

Toda esta trajetória, que propiciou a formação das raças equinas naturalizadas do Brasil, não foi fruto de uma estratégia ou planejamento, mas sim oriunda da adversidade e de acontecimentos históricos sucessivos, aliados à dedicação e visão futurista de pessoas que se esforçaram e ainda se esforçam para sua conservação e melhoramento.

Dos aspectos que conferem singularidade ao cavalo Campeiro, observa-se os geoclimáticos como fatores preponderantes de sua formação. o Planalto Catarinense apresenta pluviosidade distribuída regularmente durante todo o ano, não havendo propriamente uma estação seca. As temperaturas são amenas, com média em torno de $16,5^{\circ} \mathrm{C}$ e variação máxima de 8 a 10 graus entre verão e inverno. Nos pontos de maior altitude ocorrem geadas nas estações do outono, inverno e primavera, sendo que na região do planalto meridional, que penetra nos campos de Lages, pode ocorrer o fenômeno excepcionalmente no verão. A ocorrência de neve nos períodos de maior frio é por vezes observada em determinados locais. Embora em Santa Catarina as pastagens cultivadas venham assumindo grande importância, grande parte da pecuária da região é sustentada nos campos naturais, compostos por uma formação de gramíneas mais grosseiras e cespitosas, denominadas por espécie de Aristida, Andropogon, Schizachyrium, Elyonurus e Trachypogon (Mariante, 2000; Falcão, 2002).

Esta revisão tem por objetivo apresentar os aspectos históricos, condições atuais e perspectivas futuras do cavalo Campeiro, como ferramenta de promoção e fomento a estratégias para a conservação da raça.

\section{Estado atual da raça}

\section{Estimativa do tamanho e estrutura}

A sede atual da Associação Brasileira dos Criadores de Cavalo Campeiro (ABRACCC) está situada no Parque de Exposições Pouso do Tropeiro, na cidade de Curitibanos, SC, contando com aproximadamente 100 criadores. Segundo dados da associação, entre os anos 1985, ano de credenciamento do livro de registro oficial da raça (Stud Book), e 2016, foram registrados em torno de 1.203 equinos. Deste total, 97 machos e 845 fêmeas foram registrados em livro aberto. Para este tipo de registro os animais não precisam ter origem conhecida, mas devem atender aos requisitos morfológicos e de andamento impostos 
pela ABRACCC. Foram ainda registrados 59 machos e 202 fêmeas em livro fechado, ou seja, animais com origem conhecida e nascimento anunciado.

Em relação ao livro de registro de nascimentos, foram anunciados os nascimentos de 540 fêmeas e 432 machos, totalizando 972 animais até o ano de 2016. Para fazer parte deste livro, o pai e a mãe do potro devem ser conhecidos e devem estar registrados na ABRACCC. Estes animais devem passar por uma avalição morfofuncional no início de sua fase adulta. Caso estejam dentro do padrão morfológico e tenham como característica a marcha, sendo permitida a marcha picada, de centro (intermediária) ou batida, o animal receberá o registro definitivo; caso contrário, o animal não será marcado como Campeiro.

As figuras 1 e 2 mostram a evolução temporal do número de animais que integraram o livro de registro de nascimentos e o Stud Book, respectivamente, entre os anos de 1985 e 2014.

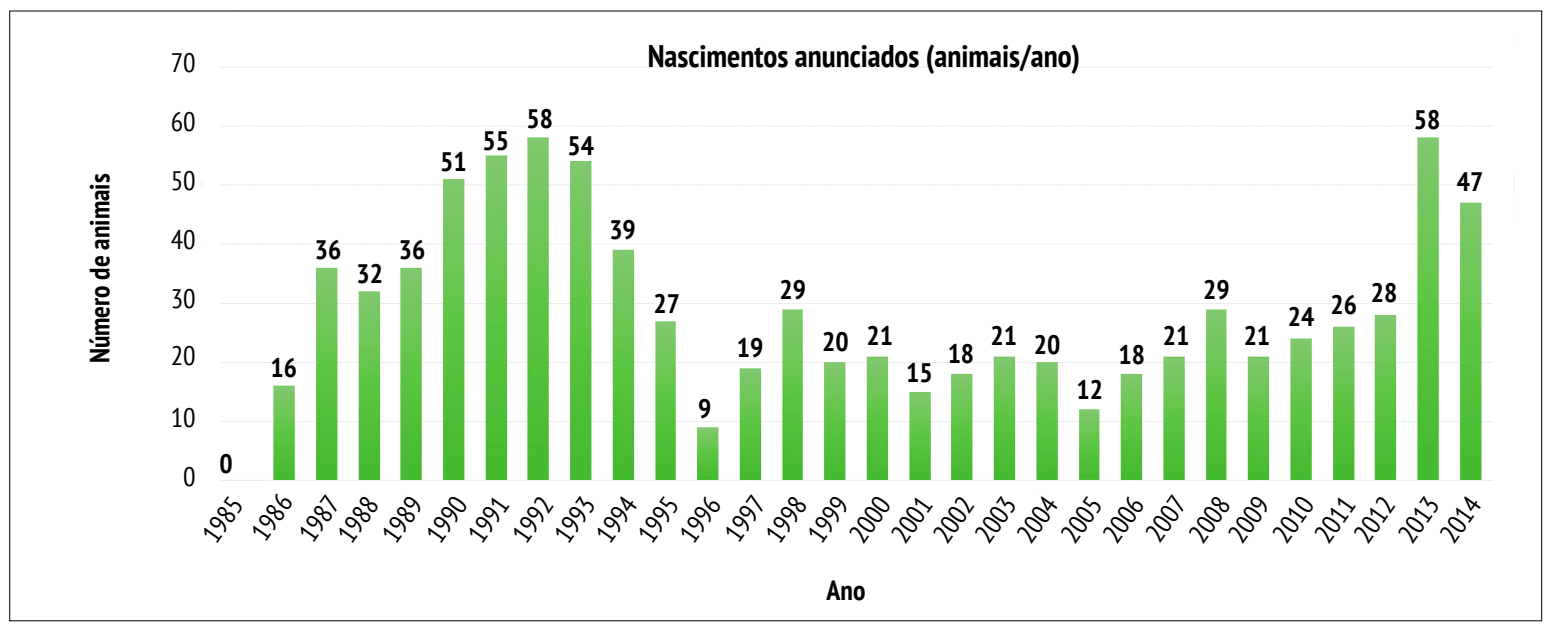

Fonte: ABRACCC.

Figura 1 - Evolução do número de cavalos Campeiros que tiveram seu nascimento anunciado no livro de registro de nascimentos da Associação Brasileira dos Criadores de Cavalo Campeiro entre 1985 e 2014.

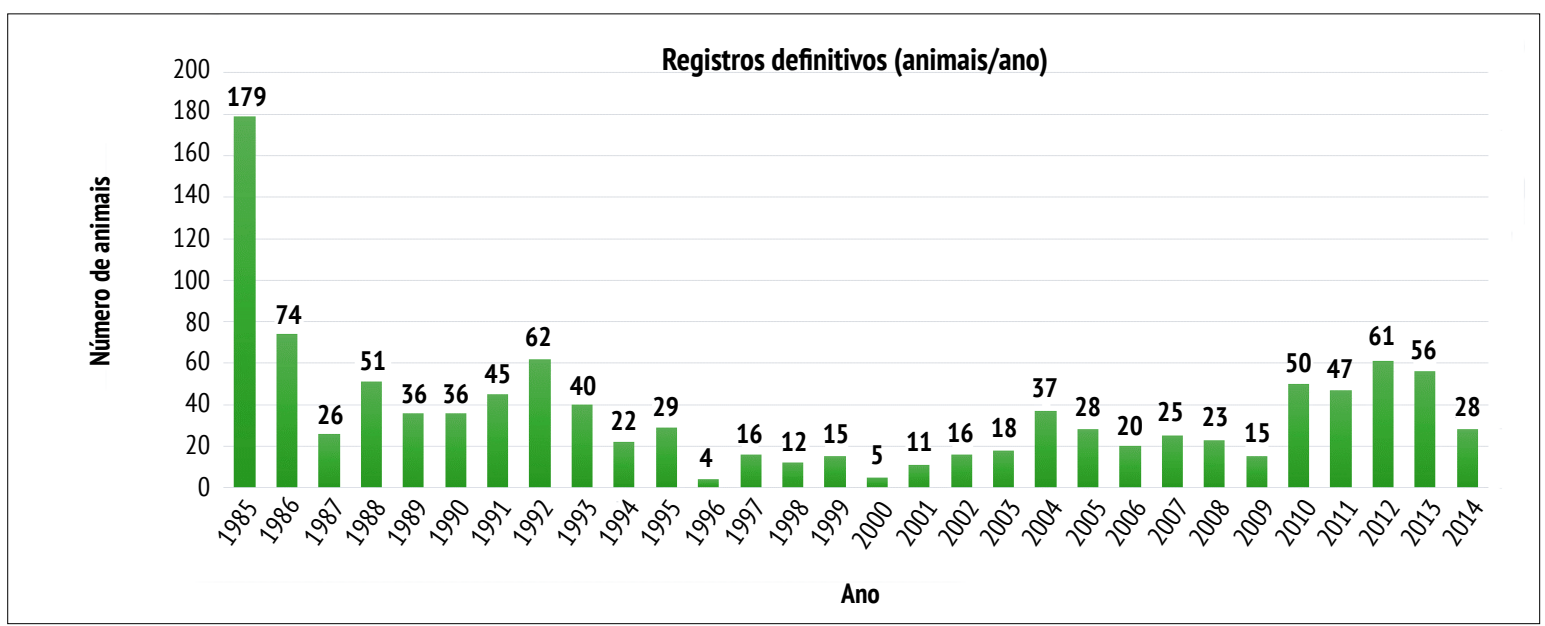

Fonte: ABRACCC.

Figura 2 - Números de cavalos Campeiros que obtiveram registro definitivo, passando a integrar o Stud Book entre 1985 e 2014. 


\section{Distribuição geográfica dentro do país}

A criação do cavalo Campeiro, antes abundante em toda a região do Planalto Catarinense e do Rio Grande do Sul e Campos Gerais do Paraná, conhecida como região dos Pinhais, que conferiu à raça a denominação "Marchador das Araucárias", está distribuída atualmente em pequenas tropas localizadas no Planalto Catarinense, principalmente nos municípios de Curitibanos e Lages, no estado de Santa Catarina (Figura 3). A fim de difundir a raça, no ano de 2010 foram formados núcleos de criadores nas cidades de Concórdia, no estado de Santa Catarina, e em Caxias do Sul, no estado do Rio Grande do Sul (Souza et al., 2016a), fazendo com que aumentasse o número de proprietários e pessoas envolvidas/interessadas.

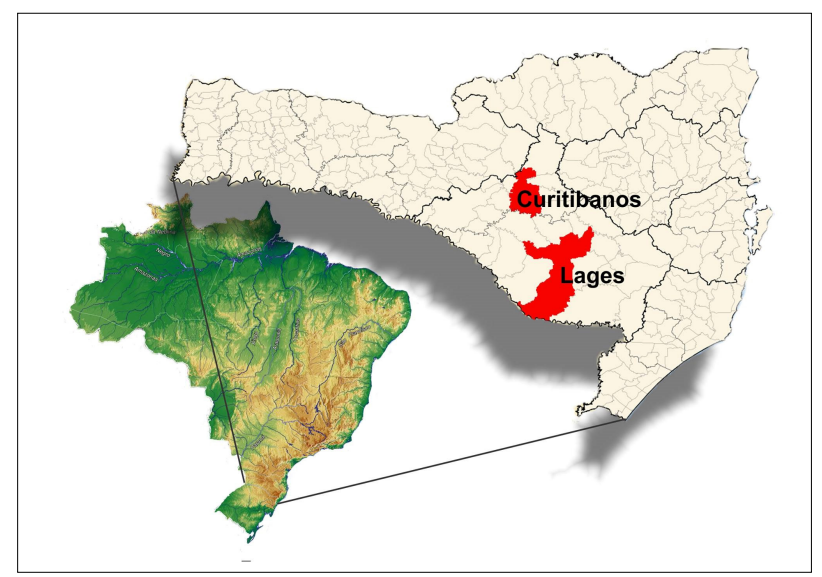

Nota: Imagem de Juliano Signor.

Figura 3 - Localização geográfica dos municípios de Curitibanos e Lages, no estado de Santa Catarina, os quais apresentam maiores altitudes com condições geoclimáticas características e onde se concentra o maior número de exemplares de equinos Campeiros, sendo os berços históricos da raça.

\section{Principais ameaças e risco de extinção}

O número de registros de cavalos Campeiros foi grande no primeiro ano da criação da associação, mas ultimamente poucos animais passaram a integrar o Stud Book, o que pode demonstrar desinteresse na criação e no registro dos equinos ou baixa qualidade zootécnica dos animais nascidos, somada ao cruzamento de indivíduos com outras raças, o que inviabiliza o registro. Um ponto relevante nesta questão é o perfil dos proprietários dos animais, que são em sua maioria usuários e não criadores, ou seja, que possuem o animal para desfrutar do conforto de seu andamento em cavalgadas, passeios ou afazeres da propriedade, optando, assim, por éguas. Estas, por sua vez, quando de boa índole, são consideradas para reprodução apenas quando estão em idade avançada, não podendo mais executar suas atividades, ou então são destinadas à reprodução aquelas que não se prestam para o serviço, o que invariavelmente vai contra as premissas do melhoramento genético equino.

Entre os anos de 2010 e 2016, a média anual de registros de machos em livro aberto e fechado foi, respectivamente, de três e quatros animais aproximadamente. Quanto às fêmeas, as médias foram, respectivamente, de 32 e 11 animais aproximadamente. Estes númeos são preocupantes se comparados com outras raças nacionais, que registram milhares de animais anualmente.

Pelo número de animais registrados nos últimos anos, nota-se o caminhar do cavalo Campeiro à extinção como raça pura e um aumento da consanguinidade no rebanho, fatos preocupantes que devem ser investigados e os motivos identificados para que medidas eficazes de correção possam ser implementadas. Tais medidas devem impulsionar a criação, que tem o potencial de agregar valor ou servir de estratégia para a conservação, fortalecimento e maior divulgação da raça, a fim de evitar a perda desse rico material genético (Falcão, 2002; Solano et al., 2013).

\section{Origem e desenvolvimento da raça}

\section{Histórico}

Os primeiros equinos trazidos ao Brasil tiveram sua origem com as primeiras viagens de exploração e colonização do continente, devido ao uso destes animais como principal meio de transporte na época. Os primeiros cavalos foram direcionados a três locais ao longo da costa brasileira: Pernambuco 
em 1535, São Vicente em 1534 e Bahia em 1549 (Torres e Jardim, 1992). Outro local importante de introdução de equinos no Brasil foi o litoral de Santa Catarina, fruto da licença expedida pelo rei a Alvar Nuñes Cabeza de Vaca, que em março de 1541 chegou à costa catarinense com duas naus e uma caravela, trazendo 400 homens e 26 cavalos de 46 que embarcaram na Espanha. A comitiva seguiu por terra a partir da foz do rio Itapocu, ao norte da ilha de Santa Catarina, transpondo a Serra do Mar e o Planalto Paranaense para atingir Assunção, no Paraguai (ABRACCC, 1984; Araújo, 1990; Soares, 2009). Especula-se que alguns desses animais se perderam durante o percurso. Também é citado o possível extravio de animais por outras expedições espanholas por esta mesma rota, visto que a ilha de Santa Catarina era o primeiro posto avançado da Espanha na América do Sul.

A partir de 1620, com o início das missões jesuíticas na região Sul do Brasil, ancorado pelo Tratado de Tordesilhas, foram introduzidos mais rebanhos bovinos e equinos. Estes animais, a posteriori, foram abandonados após as reduções serem esfaceladas pelas forças conjuntas das coroas de Portugal e da Espanha na Guerra Guaranítica (1753-1756). Estes equinos foram provavelmente os que mais fortemente contribuíram como precursores da raça Campeiro, assim como os bovinos que se sucederam na raça Crioula Lageana, típica da região dos Campos de Lages.

A primeira notícia oficial da presença de equinos vivendo livremente em Santa Catarina ocorreu no ano de 1728, por Francisco de Souza e Farias, quando da abertura do Caminho dos Conventos, que, partindo de Araranguá, SC, transpôs as matas da Serra Geral e, no planalto, deparou-se com grande número de equinos e bovinos (ABRACCC, 1984). Cristóvão Pereira de Abreu também notou a presença de animais na mesma região, utilizandose de alguns para agregar a sua tropa, registrando a domesticação inicial desses animais.

Os equinos que passaram a habitar a "Região dos Pinhais", constituída pelo Planalto Catarinense, Planalto do Rio Grande do Sul e Campos Gerais do Paraná, oriundos de ambos os episódios supra descritos (possivelmente Lusitanos), formaram um agrupamento racial chamado de "raça velha" ou "peludos". Estes animais eram capturados, domados e utilizados nas inúmeros estâncias da região. A partir da criação que levou ao aprimoramento dos equinos da "raça velha", iniciou-se a seleção dos cavalos Campeiros. A fundação da Associação Brasileira de Criadores de Cavalos Campeiros se concretizou no dia 10 de fevereiro de 1976, e sua oficialização pelo Ministério da Agricultura ocorreu em 1985, após detalhada vistoria, quando foi credenciado seu livro de registros, Stud Book, e quando se instituiu o Serviço de Registro Genealógico Oficial da Raça (CCCCN, 1984).

Uma atuação representativa da ação do homem sobre a raça se deve ao belga conhecido por Dr. Vicent que, em 1912, selecionou alguns animais, cruzando-os com garanhões Puro Sangue Inglês e Árabes, vindos da França, com o objetivo de selecionar animais mais velozes para as corridas de raias, típicas da região, e para a melhoria de sua morfologia e de atributos como beleza e funcionalidade (Mariante e Cavalcante, 2000). No entanto, não se sabe exatamente a origem racial do cavalo Campeiro atual, devido a não caracterização racial dos cavalos trazidos pelos espanhóis naquela época (Falcão, 2002).

\section{Caracterização genética}

Silva et al. (2012) buscaram estimar a variabilidade genética em cinco raças e/ou grupos genéticos de equinos naturalizados no Brasil, e sugeriram a existência de pelo menos quatro fontes de diversidade para as raças equinas brasileiras. A primeira é formada pelo Campeiro, a segunda pelo Pantaneiro e Árabe, a terceira pelo Puro Sangue Inglês e Mangalarga Marchador, e a última pelo Baixadeiro. Os resultados demonstraram que o cavalo Campeiro apresentou alelos semelhantes ao Lavradeiro e ao Baixadeiro. As maiores distâncias dos caracteres genéticos, entretanto, foram encontradas para o cavalo Campeiro, o que pode ser atribuído ao isolamento geográfico no sul do país.

Os resultados deste estudo demonstram que ocorreu perda de variabilidade genética nas cinco raças naturalizadas e, consequentemente, perda potencial das características adquiridas pelas raças durante o processo de adaptação aos 
respectivos ambientes nacionais. A limitação de seu pool genético em loci de microssatélites foi resultado de eventos de endogamia ocorridos em pequenas populações e do uso de raças exóticas como o Puro Sangue Inglês e o Árabe. Tudo isso reforça a necessidade de incluir esses rebanhos em programas de conservação de recursos genéticos animais para maximizar a variabilidade genética e conservar genes úteis.

\section{Valor da Raça}

\section{Por que conservá-la?}

O Brasil apresenta uma rica gama de raças equídeas em relação ao contexto mundial, contando com pelo menos 23 raças, sendo que 11 destas foram formadas nos limítrofes do país. Entre estas, têm-se ainda sete raças de equídeos com andamento natural marchado, em que cada uma apresenta características morfológicas e funcionais específicas, tornando-as singulares: Pêga, Campolina, Piquira, Pampa, Mangalarga Marchador, Mangalarga e Campeiro. 0 cavalo Campeiro é umas das poucas raças de marchadores que ainda mantém suas características naturais de andamento, que traz naturalidade, qualidade e, principalmente, diversidade para atender os diferentes anseios e necessidades dos mais diversos tipos de proprietários e usuários.

\section{Potencial de uso presente e futuro}

Equinos da raça Campeiro foram classificados como animais de sela e tração leve em virtude se suas características morfológicas. Devido à rusticidade, leveza e resistência para trabalho de sela e tração ligeira, estes equinos são muito utilizados na região para provas hípicas, destacando-se o tiro de laço, ou laço comprido, e cavalgadas. A docilidade, a beleza e a marcha em quatro tempos, que fornece conforto ao cavaleiro e é sua principal característica, são atributos que fazem com que o cavalo Campeiro seja muito apreciado e adaptado para a utilização em longas cavalgadas, sendo também utilizado para o dia a dia na lida com o gado e em rodeios (CCCCN, 1983; Falcão, 2002).
A equinocultura caminha cada vez mais para a finalidade de lazer e esporte, sendo o cavalo Campeiro dotado de qualidades que contemplam os objetivos dessa exploração, caracterizada pela docilidade e andamento, que proporcionam grande conforto ao cavaleiro. Há, também, a forte identidade com relação à cultura local e à criação do cavalo Campeiro, pois são sólidas as questões ligadas à tradição, à herança familiar e ao uso desse recurso genético no trabalho e lazer rural (Solano et al., 2013).

\section{Caracterização da Raça}

\section{Características fenotípicas}

O Campeiro pode ser classificado como um cavalo de pequeno a médio porte, sendo esta a menor parcela da população, com boas proporções e boa estrutura para hipismo. Os machos são registrados com alturas de cernelha entre 1,42 a 1,54 m e fêmeas entre 1,40 e 1,52 m. 0 cavalo é intermediário entre cavalo de sela e tração leve, com peso médio de $419 \mathrm{~kg}$. Seu andamento principal é descrito como marcha típica (Falcão, 2002).

Todas as pelagens são aceitas para registro, com exceção das conjugadas (pampa ou tobiana, oveira, leopardo e mantada) e albinoides. As pelagens mais comuns são o castanho, baio e tordilho, em todas as suas variações. A cabeça apresenta a fronte de retilínea a subconvexa, o chanfro de retilíneo a subcôncavo, orelhas medianas e ativas, olhos vivos e bem implantados. A garupa é harmoniosamente inserida à região lombar, ampla, suavemente inclinada, com musculatura glútea bem definida formando uma única região, e os membros são de estrutura leve e bem aprumados. Em geral, apresenta boas proporções, porém com altura da cernelha inferior a da garupa (McManus et al., 2005).

\section{Características adaptativas}

Pelas condições peculiares de clima, alimentação, manejo e seleção nas quais os equinos da raça Campeiro se desenvolveram e são mantidos, acredita-se que possam ocorrer, como consequência, 
adaptações fisiológicas compensatórias, principalmente em relação aos sistemas cardiovascular e hematopoético, sendo de extrema importância o conhecimento dos padrões fisiológicos da raça e suas variações para uma correta interpretação dos exames complementares utiliza-dos no auxílio diagnóstico de enfermidades.

Souza et al. (2016b), ao mesurarem o perfil bioquímico sérico de equinos Campeiros, observaram que os valores médios de aspartato aminotransferase (AST), fosfatase alcalina (FA), alanina aminotransferase (ALT), ureia e creatinina foram semelhantes aos propostos na literatura para outras raças. Os valores de creatina quinase (CK), gama glutamil transpeptidase (GGT) e lactato desidrogenase (LDH), entretanto, foram superiores aos comumente utilizados como referência. Não houve diferença nas concentrações de nenhum dos componentes séricos avaliados nas diferentes faixas etárias avaliadas. Maiores valores médios nas concentrações de ureia e menores de creatinina foram observados nas fêmeas em relação aos machos, assim como maior atividade sérica de FA em fêmeas gestantes em relação às éguas vazias. Com isso, concluiu-se que o perfil bioquímico sérico de equinos sadios da raça Campeiro apresenta variações peculiares que devem ser levadas em consideração na interpretação de exames laboratoriais.

Fonteque et al. (2016), ao estudarem o perfil hematológico desses animais, identificaram que os valores da hemoglobina corpuscular média (HCM), volume corpuscular médio (VCM) e número total de eosinófilos apresentaram algumas diferenças nas faixas etárias estudadas. Também houve diferença para as variáveis proteína total plasmática e número total de eosinófilos quando comparadas fêmeas prenhas e vazias. A partir desses resultados, semelhantes ao anterior, pôdese concluir que os equinos Campeiros apresentam particularidades com relação às variáveis do hemograma, proteínas totais e fibrinogênio plasmático quando comparados aos descritos por outros autores em outras raças.

Souza et al. (2016c), ao realizarem a podometria dos cavalos Campeiros, observaram que os membros torácicos apresentaram cascos com maior comprimento e largura, além de maior comprimento de ranilha em relação aos pélvicos. A relação peso vivo:área do casco foi similar entre membros, e os cascos apresentaram tamanho adequado em relação ao peso vivo do animal. Observou-se elevada frequência de contração de ranilha, principalmente em membros torácicos. Encontrou-se, entretanto, baixa frequência de desequilíbrios lateromediais. Concluiu-se que os equinos da raça Campeiro apresentam conformação podal similar a outras raças, embora investigações mais específicas devam ser realizadas. As práticas de casqueamento adotadas pelos proprietários devem ser revistas e melhoradas frente à alta frequência de contração de ranilha.

Souza et al. (2016d), ao estudarem o perfil eletroforético das proteínas séricas do cavalo Campeiro, identificaram que os valores médios das frações séricas estiveram dentro do intervalo de referência proposto para a espécie. Observaram maior valor de gamaglobulinas nos animais acima de 13 anos de idade, proteinograma sérico similar entre machos e fêmeas e, em éguas prenhes em relação às vazias, observaram maiores valores de alfa 1 e de gamaglobulinas e menor relação A:G.

Souza et al. (2017), ao mesurarem o teor de sete minerais nos cascos dos equinos Campeiros, mostraram que independente da pigmentação dos cascos, observaram-se maiores teores de $\mathrm{Cu}$, Fe e $\mathrm{Zn}$ na parede e de $\mathrm{K}, \mathrm{Ca}$ e $\mathrm{Mg}$ na ranilha, não havendo diferença nos teores de Na entre as regiões do casco. Em relação aos cascos pigmentados (escuros) e não pigmentados (claros), observaram maiores teores de Fe na parede e sola e de K na sola e na ranilha dos cascos pigmentados. Os autores discutem que embora existam diferenças nos teores de alguns minerais entre cascos de diferentes colorações, isso parece não refletir em melhor qualidade do casco escuro em relação ao claro nos equinos da raça Campeiro.

\section{Características funcionais}

Por se tratar de uma raça de marcha, os diferentes aspectos relacionados ao bom desenvolvimento desse andamento são os pontos fundamentais da funcionalidade do cavalo Campeiro. Durante um concurso funcional, os árbitros avaliam estilo, rendimento, regularidade, comodidade e diagrama 
da marcha. Animais que apresentam andamento do tipo trote ou andadura não são registrados.

Fonteque et al. (2015) avaliaram o andamento por meio de análise de vídeo de 113 equinos da raça Campeiro e observaram que 36 animais apresentavam marcha incompleta, 74 marcha completa e três animais apresentaram a guinilha como andamento. Dos equinos com marcha completa, 20 animais apresentaram marcha batida, 14 apresentaram marcha de centro (intermediária) e 40 apresentaram marcha picada. Aproximadamente $65 \%$ dos animais utilizados neste estudo apresentaram a marcha completa e, destes, quase $48 \%$ exibiram a marcha de centro ou picada, descritas como as de melhor qualidade (Figura 4) (Toledo, 2006).

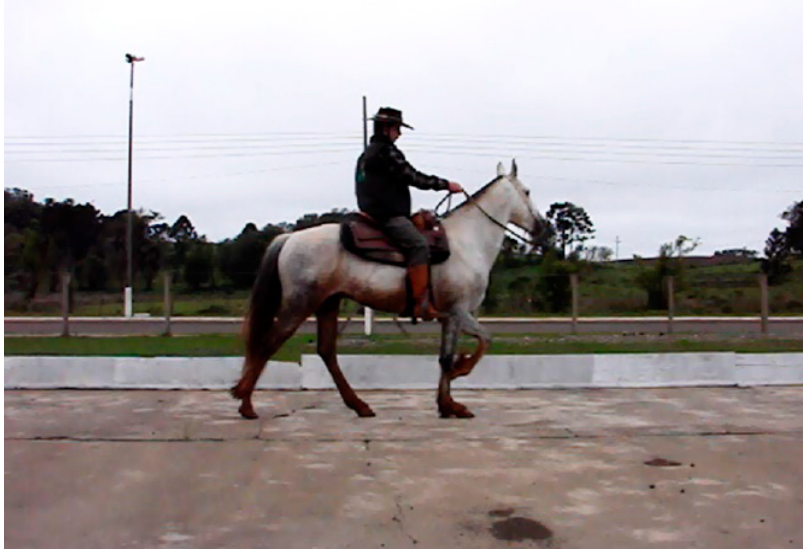

Nota: Foto de Joandes Henrique Fonteque.

Figura 4 - Equino da raça Campeiro no momento da avaliação da marcha por meio de filmagem, demonstrando o tríplice apoio em uma marcha picada.

\section{Manejo reprodutivo}

Há poucos dados na literatura sobre os aspectos reprodutivos dos animais da raça Campeiro. Observa-se, entretanto, que os nascimentos ocorrem durante todo o ano, sendo o principal período entre setembro e janeiro (Falcão, 2002). A monta natural é o sistema mais utilizado pelos criadores, porém há propriedades que realizam monta controlada
(Figura 5). Mais recentemente, observa-se a utilização de biotécnicas mais avançadas, como a inseminação artificial e a transferência de embriões, estratégias estas fundamentais para acelerar a criação.

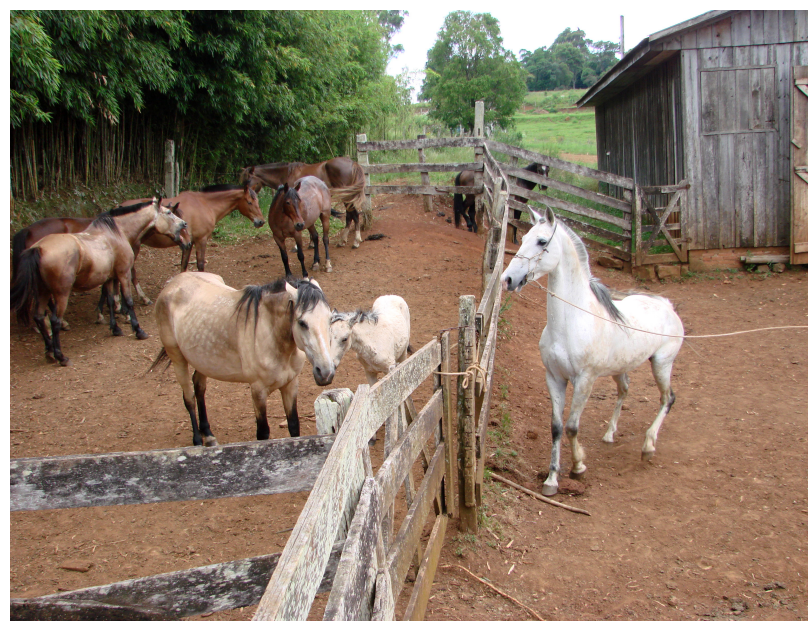

Nota: Foto de Joandes Henrique Fonteque.

Figura 5 - Método de rufiação para identificação de cio nas fêmeas. 0 garanhão fica separado das éguas para evitar acidentes.

Ao se estudar os aspectos reprodutivos de éguas da raça Campeiro nas condições da região CentroOeste do Brasil (Nascimento, 2014), identificouse que estas apresentaram pouca interferência sazonal, apresentando ciclos estrais todo o ano. Os aspectos relacionados à duração do ciclo estral, dia da divergência e tamanho folicular, dia da dominância e folículo dominante, folículo préovulatório, características ultrassonográficas do útero, tamanho do corpo lúteo e tônus uterino são similares às outras raças. A utilização de técnicas que reduzam o intervalo de anestro pode otimizar a utilização destes animais na reprodução.

\section{Sistema de criação}

As condições naturais nas quais ocorreu todo o processo de formação da raça Campeiro ainda é realidade em muitas propriedades nos 
municípios de Lages e Curitibanos, em que as manadas permanecem em extensas áreas de pastagem nativa, sendo estabuladas apenas para realização de manejos inerentes à criação (controle de endo e ectoparasitos, revisão dos potros, marcação, cuidados com os cascos) ou para serem utilizadas para afazeres na propriedade (Figura 6). Entretanto, com a aquisição de animais por novos adeptos, observa-se que muitos animais estão sendo mantidos em hospedarias e em pequenas instalações nas propriedades para serem utilizados para lazer. Deste modo, passam a receber maior atenção aos cuidados estéticos, alimentação, casqueamento, ferrageamento e assistência veterinária, ou seja, uma maior profissionalização da criação, algo esperado e que tende a crescer.

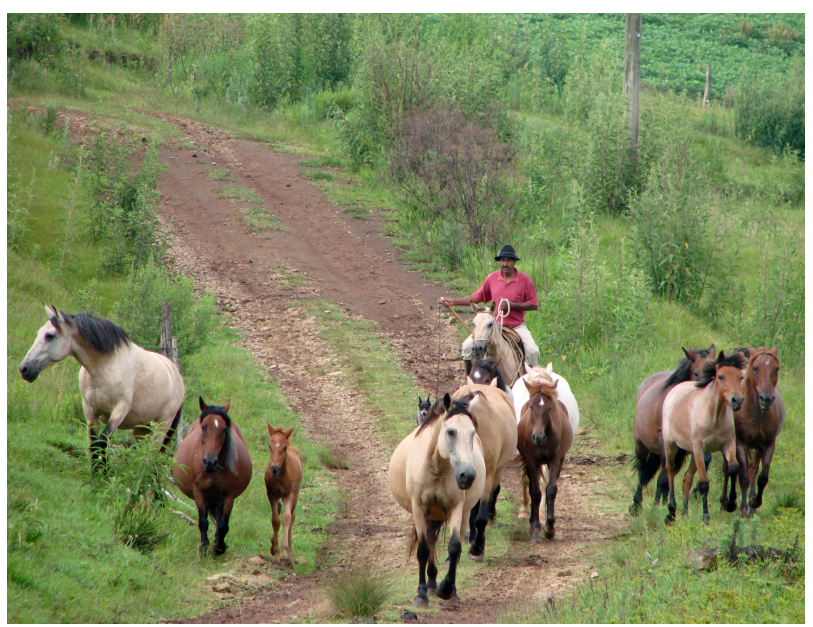

Nota: Foto de Joandes Henrique Fonteque.

Figura 6 - Lote de éguas Campeiras prenhas e/ou com potro ao pé sendo conduzidas para a sede da propriedade para realização de cuidados sanitários.

Solano et al. (2011), ao entrevistarem 11 criadores de cavalos Campeiros nos municípios de Campos Novos, Curitibanos e Lages, em Santa Catarina, com o objetivo de caracterizar o sistema de criação na região Sul do Brasil, identificaram que o tamanho médio das propriedades era de 260 hectares, sendo que $45,5 \%$ eram de até 50 ha, $27,5 \%$ entre 50 e 300 ha e $27,5 \%$ mais de 300 ha. Dentre os entrevistados, $45,5 \%$ não se consideram criadores e sim proprietários, devido ao pequeno número de equinos, em que 54,5\% dos entrevistados tinham até 10 equinos, 36,4\% entre 10 e 30 e apenas $9 \%$ possuíam mais de 30 animais, sendo que apenas $9 \%$ obtinham renda com a criação do cavalo Campeiro.

Neste estudo, constatou-se ainda que o sistema de criação utilizado era majoritariamente o extensivo (100\%), salvo os casos em que alguns animais, utilizados diariamente ou nos períodos de exposições, eram mantidos estabulados, recebendo ração, milho e alfafa. Grande parte se alimentava de pastagens nativas durante o verão e cultivadas durante o inverno $(45,5 \%)$. Observouse, também, que a comercialização dos animais era esporádica para a maioria dos criadores $(81,5 \%)$ e não era realizada por $18,5 \%$ dos entrevistados. Estes dados propuseram a conclusão de que há pouca especialização na comercialização dos cavalos Campeiros.

\section{Análise SWOT}

Atualmente amplamente utilizada nas mais diversas áreas, a análise SWOT estuda a competitividade de uma organização segundo quatro variáveis: strengths (forças), weaknesses (fraquezas),opportunities (oportunidades) ethreats (ameaças). Através destas variáveis, pode-se fazer a identificação das qualidades e defeitos intrínsecos e das variáveis ambientais que influenciam a organização de interesse. É uma ferramenta utilizada para a realização de análise de ambiente e serve de base para planejamentos estratégicos e de gestão de uma organização (Gürel e Tat, 2017).

A ferramenta foi aplicada ao cavalo Campeiro de forma que os fatores identificados fossem separados em dois ambientes, interno e externo. 0 ambiente interno foi definido como os fatores que podem ser modificados ou manipulados pelo criador, enquanto o ambiente externo são os fatores que não dependem da ação direta do criador. Os pontos apresentados nas variáveis resumem os assuntos discutidos ao longo deste artigo, auxiliando a fixar e evidenciar as questões que estão adequadas e as que precisam ser melhoradas (Quadro 1). 
Quadro 1 - Análise SWOT da raça Campeiro

\begin{tabular}{|c|c|c|}
\hline & Fatores Positivos & Fatores Negativos \\
\hline 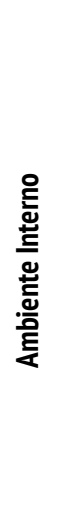 & $\begin{array}{l}\text { Forças } \\
\text { - Andamento marchado. } \\
\text { - Rusticidade. } \\
\text { - Docilidade. } \\
\text { - Adaptabilidade à região de origem. } \\
\text { - Valor de mercado atraente. } \\
\text { - Porte adequado para equitação. } \\
\text { - Associação de Criadores e Serviço de Registro Genealógico } \\
\text { formados e atuantes. } \\
\text { - Formação de núcleos de conservação. } \\
\text { - Participação dos criadores em exposições e competições. }\end{array}$ & $\begin{array}{l}\text { Fraquezas } \\
\text { - População pequena. } \\
\text { - Consanguinidade. } \\
\text { - Poucos nascimentos anunciados anualmente. } \\
\text { - Baixo número de animais registrados anualmente. } \\
\text { - Fêmeas destinadas à reprodução de baixo potencial melhorador e/ } \\
\text { ou com idade avançada. } \\
\text { - Baixa profissionalização na criação. }\end{array}$ \\
\hline 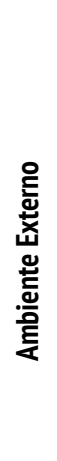 & $\begin{array}{l}\text { Oportunidades } \\
\text { - Fonte para realização de estudos científicos. } \\
\text { - Reconhecimento nacional. } \\
\text { - Organização de competições funcionais com outras raças } \\
\text { marchadoras nacionais e internacionais. } \\
\text { - Melhoria do treinamento e condicionamento dos animais. } \\
\text { - Maior atenção aos aspectos nutricionais e sanitários dos animais. } \\
\text { - Forte apelo histórico, regional e cultural. }\end{array}$ & $\begin{array}{l}\text { Ameaças } \\
\text { - Registro de animais sem origem conhecida (Livro Aberto). } \\
\text { - Maioria dos proprietários com perfil de usuários e não de } \\
\text { criadores. } \\
\text { - Não registro de animais de pelagens conjugadas (pampa e oveiro). } \\
\text { - Não registro de animais castrados. } \\
\text { - Baixo número de técnicos credenciados pela associação. } \\
\text { - Metas de seleção não claramente definidas. } \\
\text { - Baixo interesse das novas gerações das famílias em perpetuar a } \\
\text { criação. }\end{array}$ \\
\hline
\end{tabular}

\section{Perspectivas para a raça}

A continuidade e a elaboração de mais projetos de pesquisa são instrumentos fundamentais na formação de conhecimento técnico-científico que possa ser implementado na criação e seleção, buscando um animal aprimorado e com identidade genuína. Neste tocante, a tarefa de desenvolver a consciência de apreço, manutenção e expansão da raça nas gerações mais novas, bem como o acolhimento de todos os novos interessados, é obrigação de todos os atuais envolvidos. Somente assim haverá a perpetuação do cavalo Campeiro.

\section{Conclusão}

O cavalo Campeiro tem uma história relativamente curta comparada às grandes raças mundiais, fazendo com que haja pela frente um longo caminho de trabalho, seleção, estudos e divulgação. Estes fatores devem ser espelhados em estratégias que tiveram sucesso em outras raças, podendo, assim, avançar de forma rápida, porém segura, sem nunca esquecer a história e a tradição que foram o gatilho da formação dessa promissora raça.

O rumo da criação de cavalos Campeiros deve estar direcionado para aquilo que é de mais útil, seu andamento. Esta deve ser a preocupação principal de seus técnicos e criadores ao avaliarem e selecionarem os animais, estando associado ao componente morfológico funcional e não ao estético. A marcha é indiscutivelmente sua maior e melhor característica, e mesmo sendo de caráter natural e espontâneo, a profissionalização do treinamento e condicionamento é algo emergente e necessário para que haja competitividade com as demais raças marchadoras do Brasil, podendo culminar em competições funcionais entre estas, levando a uma projeção nacional da raça. 


\section{Referências}

Araújo RV. Os Jesuítas dos sete povos. Canoas: La Salle; 1990. 467 p.

Associação Brasileira dos Criadores de Cavalos Campeiros - ABRACCC. Campeiro, o marchador das araucárias. Curitibanos: Panfleto; 1984. 6 p.

Comissão Coordenadora da Criação do Cavalo Nacional

- CCCCN. Estudo da evolução, fomento, preservação

e seleção do cavalo Campeiro. Brasília: Ministério da Agricultura; 1984. 14 p.

Comissão Coordenadora da Criação do Cavalo Nacional - CCCCN. Anuário. Brasília: Ministério da Agricultura; $1983.87 \mathrm{p}$.

Falcão RF. Variação genética, fenotípica e caracterização do cavalo Campeiro [dissertação]. Brasília: Universidade de Brasília; 2002. 72 p.

Fonteque JH, Ceccatto ML, Bagio RM, Schade J, Saito ME, Martins VV, et al. Hematological profile, total plasma protein and fibrinogen concentrations of clinically healthy adult Campeiro horses. Cienc Rural. 2016;46(1):144-9.

Fonteque JH, Pereira LMA, Souza AF, Dresch A, Costa D. Relação entre medidas lineares e angulares e a qualidade da marcha em equinos da raça Campeiro. $25^{\circ}$ Seminário de Iniciação Científica UDESC; 23-24 set 2015; Lages, SC. Florianópolis: UDESC; 2015.

Gürel E, Tat M. Swot analysis: A theoretical review. J Inter Soc Res. 2017;10(51):994-1006.

Mariante AS, Cavalcante N. Animais do Descobrimento. Raças Domésticas da História do Brasil. Brasília: Embrapa; 2000. 232 p.

McManus C, Falcão RA, Spritze A, Costa D, Louvandini H, Dias LT, et al. Caracterização morfológica de equinos da raça Campeiro. R Bras Zootec. 2005;34(5):1553-62.

Nascimento JN. Caracterização do ciclo estral de éguas da raça Pantaneiro e Campeiro no planalto central [dissertação]. Brasília:UniversidadedeBrasília;2014.41p.
Santos SA, Sereno JRB, Mazza MCM, Mazza CA. Origin of the Pantaneiro horse in Brazil. Arch Zootec. 1992;41(extra):371-81.

Silva ACM, Paiva SR, Albuquerque MSM, Egito AA, Santos SA, Lima FC, et al. Genetic variability in local Brazilian horse lines using microsatellite markers. Genet Mol Res. 2012;11(2):881-90.

Soares 0. 0 andarilho das Américas - Cabeza de Vaca. Ponta Grossa: UEPG; 2009. 140 p.

Solano GA, Silva MC, Rocha FEC, Silva DC, Lopes FB, Fioravanti MCS, et al. Análise do discurso de criadores de cavalo Campeiro no Sul do Brasil: Instrumento de diagnóstico para conservação e fortalecimento da raça. Act Iberoam Conserv Anim. 2013;3:8-14.

Solano GA, Silva MC, Sereno JRB. Aspectos sobre o sistema de criação de cavalo Campeiro no Sul do Brasil. Act Iberoam Conserv Anim. 2011;1:405-7.

Souza AF, Granella MCS, Fonteque JH, Silva AD. Cavalo Campeiro: O Marchador das Araucárias. SB Rural; 2016a [citado 16 fev 2018]. Disponível em: https://tinyurl.com/ ybadrkz8.

Souza AF, Mendes RP, Granella MC, Casa MS, Laus R, Moreira MA, et al. Teores de sete minerais nos cascos de equinos da raça Campeiro. $\mathrm{R}$ Acad Cienc Anim. 2017;15(Supl 1):S107-8.

Souza AF, Mendes RP, Laus R, Moreira MA, Schade J, Casa MS, et al. Biometria do equilíbrio podal de equinos da raça Campeiro. $4^{\circ}$ Congresso Brasileiro de Recursos Genéticos; 8-11 nov 2016; Curitiba, PR. Brasília: Sociedade Brasileira de Recursos Genéticos; 2016c. p. 50.

Souza AF, Schade J, Kunz JR, Ramos AF, Albuquerque MSM, Fonteque GV, et al. Perfil bioquímico sérico de equinos clinicamente sadios da raça Campeiro. Arq Bras Med Vet Zootec. 2016b;68(4):839-44.

Souza AF, Schade J, Ramos AF, Albuquerque MSM, Fonteque GV, Costa D, et al. Perfil eletroforético das proteínas séricas de equinos clinicamente sadios da raça Campeiro. $4^{\circ}$ Congresso Brasileiro de Recursos Genéticos; 
8-11 nov 2016; Curitiba, PR. Brasília: Sociedade Brasileira de Recursos Genéticos; 2016d. p. 100.

Toledo AP. A locomoção dos equídeos - O livro da marcha. São José dos Campos: Toledo Horse; 2006. 122 p.

Torres AP, Jardim WR. Criação do Cavalo e de Outros Equinos. São Paulo: Nobel; 1992. 654 p. 